\title{
THE EFFECT OF ELEVATION ON THE DISTRIBUTION OF SIBLING SPECIES IN THE SIMULIUM ARCTICUM COMPLEX (DIPTERA: SIMULIIDAE)
}

\author{
Gerald F. Shields ${ }^{1,2}$, Gregory M. Clausen ${ }^{1}$, Christina S. Marchion ${ }^{1}$, Tracy L. Michel ${ }^{1}$, \\ Kathryn C. Styren ${ }^{1}$, Callie N. Riggin ${ }^{1}$, Tonya D. Santoro ${ }^{1}$, and Lindee M. Strizich ${ }^{1}$
}

\begin{abstract}
At least 5 sibling species and an additional 11 cytotypes of the Simulium arcticum complex occur in Montana. Consequently, this speciose complex might allow study of environmental correlates with genetic differentiation. We used conventional methods of collection and cytogenetic analysis to study 1128 male larvae of the Simulium arcticum complex at 15 sites within 5 drainages in western Montana to test the hypothesis that distribution of siblings is associated with elevation. We sampled at the mouth, at the headwaters, and at an intermediate site to span the range of elevations within each drainage. We restricted our analyses to the most abundant taxa of the S. arcticum complex within our study area and observed a statistically significant presence of S. apricarium at low-elevation sites. Simulium arcticum IIL-18 appeared more frequently than expected at high elevation sites. Simulium brevicercum and S. arcticum sensu strictu appeared to be distributed randomly. We suggest potential causal reasons for these distributions including differential use of habitats along these elevational gradients.
\end{abstract}

Key words: black flies, chromosomal rearrangements, sibling species, elevation, sibling distributions.

Black flies (Diptera: Simuliidae) are often composed of cytologically differentiated and reproductively isolated sibling species (cytospecies), which can be observed when polytene chromosomes of larval salivary glands are analyzed (Rothfels 1979). The recognition of sibling species is based on sex-linked rearrangements, fixed chromosomal inversions, autosomal polymorphisms, the presence or absence of B chromosomes, or a combination of all these (Rothfels 1956, Rothfels et al. 1978, Shields and Procunier 1982, Newman 1983, Procunier and Shemanchuk 1983, Allison and Shields 1989). Often, sex-linked chromosomal rearrangements occur as paracentric inversions that are heterozygous in males and homozygous in females, with males of each sibling having a unique inversion. The numerous discoveries of reproductively isolated siblings of black flies among what were originally considered by conventional taxonomists as single morphospecies suggest that these chromosomal rearrangements promote or at least accompany the diversification process in these insects. The prevalence of sibling species among morphospecies of black flies provides an opportunity to investigate the causes of sibling distribution and to describe adaptation at the local level. Studies that test hypotheses about the causal determinants of distribution and attempt to explain reasons for the mechanisms of site selection by various black fly siblings are important and largely unexplored (Adler et al. 2004).

The Simulium arcticum complex of western North America is a case in point. We originally described 5 siblings (S. arcticum-standard, arcticum IIL-1, arcticum IIL-2, arcticum IIL-3, and arcticum IL-3.4) of this complex from Alaska and western Canada (Shields and Procunier 1982). These siblings have now been formally recognized as $S$. brevicercum, S. arcticum IIL-1, S. saxosum, S. arcticum sensu strictu (s.s.), and S. negativum, respectively (Adler et al. 2004). Two additional siblings, S. arcticum IIL8.9/IIS-10.11 (S. vampirum; Adler et al. 2004) and S. arcticum IIS-4, were subsequently described from the Athabasca River drainage of Alberta, Canada, by Procunier and Shemanchuk (1983) and by Procunier (1984), respectively. Two more sibling species, S. apricarium, and $S$. chromatinum, have recently been recognized (Adler et al. 2004). An additional 16 taxa of the S. arcticum complex have been described as cytotypes (populations having unique sex-linked chromosomal rearrangements but for which there is yet no firm evidence of

\footnotetext{
${ }^{1}$ Department of Natural Sciences, Carroll College, 1601 N. Benton Avenue, Helena, MT 59625-0002.

2E-mail: gshields@carroll.edu
} 
TABLE 1. Abundance (frequency of siblings/cytotypes) and distribution of the 4 major taxa of the Simulium arcticum complex at 15 sites ( 3 sites within each of 5 drainages). Elevations and ranges of water temperatures are given for each site.

\begin{tabular}{|c|c|c|c|c|c|c|}
\hline \multirow[b]{2}{*}{ Drainage and site } & \multirow[b]{2}{*}{$\begin{array}{l}\text { Elevation } \\
(\mathrm{m})\end{array}$} & \multirow{2}{*}{$\begin{array}{c}\text { Temperature } \\
\text { range } \\
\left({ }^{\circ} \mathrm{C}\right)\end{array}$} & \multicolumn{4}{|c|}{ Frequency of siblings/cytotypes } \\
\hline & & & S. brevicercum & S. arcticum s.s. & S. apricarium & $\begin{array}{l}\text { S. arcticum } \\
\text { IIL-18 }\end{array}$ \\
\hline \multicolumn{7}{|l|}{ BOULDER RIVER } \\
\hline Bison Creek & 1661 & $2-15$ & 19 & 29 & 1 & 1 \\
\hline High Ore & 1479 & $2-10$ & 9 & 54 & 0 & 1 \\
\hline Cardwell & 1260 & $7-15$ & 0 & 0 & 54 & 0 \\
\hline \multicolumn{7}{|c|}{ LitTle BlaCKFOOT RivER } \\
\hline Kading C. & 1720 & 8 & 7 & 2 & 0 & 1 \\
\hline Elliston & 1478 & $7-12$ & 111 & 61 & 0 & 40 \\
\hline Garrison & 1263 & $9-18$ & 4 & 3 & 56 & 0 \\
\hline \multicolumn{7}{|l|}{ Trout Creek } \\
\hline Vigilante C. & 1424 & $10-12$ & 1 & 1 & 0 & 0 \\
\hline Mile 6.1 & 1349 & $10-12$ & 25 & 8 & 0 & 0 \\
\hline Mouth & 1193 & $8-13$ & 32 & 8 & 85 & 0 \\
\hline \multicolumn{7}{|l|}{ Flint Creek } \\
\hline Campground & 1606 & $10-13$ & 26 & 18 & 0 & 7 \\
\hline Philipsburg & 1473 & $12-14$ & 24 & 14 & 3 & 4 \\
\hline Hall & 1275 & $5-16$ & 20 & 8 & 9 & 2 \\
\hline \multicolumn{7}{|c|}{ CANYON CREek/LitTle } \\
\hline \multicolumn{7}{|c|}{ PRICKLY PEAR } \\
\hline Canyon Creek & 1335 & $6-13$ & 20 & 65 & 0 & 5 \\
\hline LPPC & 1148 & $3-11$ & 0 & 179 & 56 & 0 \\
\hline Mouth & 1056 & $8-12$ & 0 & 37 & 18 & 0 \\
\hline
\end{tabular}

reproductive isolation; Adler et al. 2004, Shields unpublished data). With additional cytogenetic analyses, particularly where 2 or more cytotypes are found in sympatry, and additional morphological study, these types may prove to be good biological species as well.

The presence of 9 species and an additional 16 potential cytospecies within this complex suggests, not only extreme genetic diversity, but also the potential to study environmental correlates with the taxon-specific chromosomal variation. Given the diversity of types within our study area, we speculated that some might be adapted to higher mountainous regions and to colder temperatures in spring while others might be adapted to lowland/prairie locations where temperatures of streams are generally higher. We know that altitude affects species diversity in black flies given that 63 species have been found in the Sierra Nevada region of California, whereas only 28 species occur in the prairie region of North Dakota south to Oklahoma, an area 12 times larger than the Sierra Nevada region (Adler et al. 2004).

We studied the cytogenetics of the 4 most abundant taxa of the $S$. arcticum complex in west central Montana: S. brevicercum, S. arcti- cum s.s., S. apricarium, and S. arcticum IIL-18 (see Results and Discussion for a description of this taxon). Given the diversity within the S. arcticum complex here, we hypothesized that 1 or more types might be characterized by differential use of habitats along elevational gradients. Alternatively, if no ecological habitat selection were operative, the taxa would be randomly distributed throughout the 5 drainages.

\section{Methods}

We sampled 15 collection sites in 5 different drainages (Table 1) at monthly intervals from April through August. We acknowledge that elevations for the 3 categories: high, intermediate, and low-are not consistent among drainages; rather, we emphasize elevational differences within drainages. All sites were sampled by a minimum of 3 researchers, who spent equal amounts of time (usually 45-60 minutes) at each site sampling all substrates including trailing vegetation, rocks, branches, and logs. All larvae of black flies, regardless of species, were removed with forceps and placed in a vial containing fresh, cold Carnoy's fixative (3 parts $100 \%$ ethanol: 1 part glacial acetic 


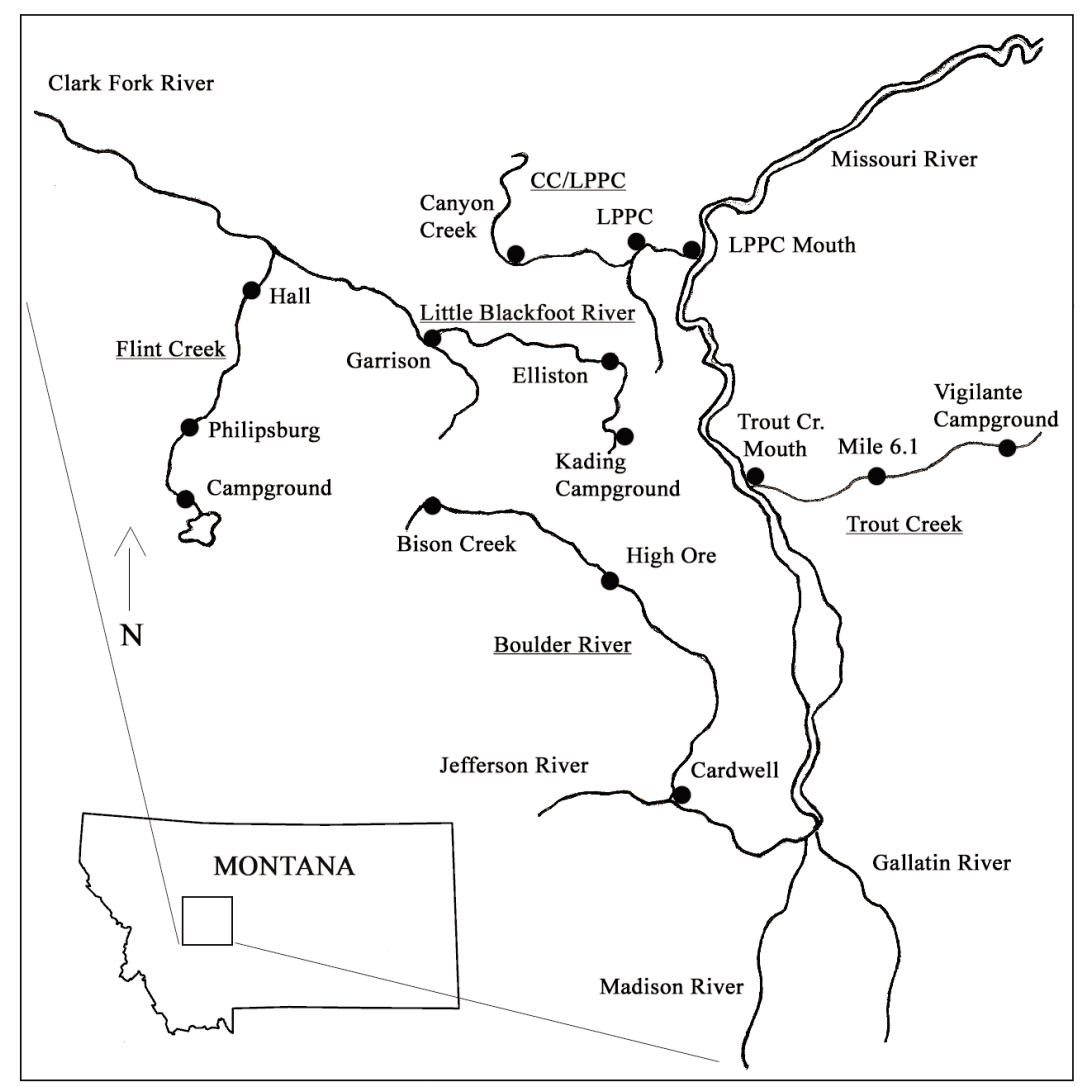

Fig. 1. Regional map of west central Montana indicating the 5 drainages and 15 collection sites at which abundance and presence-absence frequencies of Simulium brevicercum, S. arcticum s.s., S. apricarium, and S. arcticum IIL-18 were determined. The 5 drainages are underlined while enclosed circles designate the 3 sites (high, intermediate, and low) within each of these drainages at which larvae were collected. CC_Canyon Creek, LPPC_Little Prickly Pear Creek.

acid). Collection vials were placed on wet ice until we returned to the laboratory where the Carnoy's fixative was changed repeatedly until it appeared colorless (usually 4 changes). At each site we recorded temperature of stream water to the nearest degree centigrade and elevation to the nearest meter with a Suunto portable altimeter. The altimeter was calibrated to $1181 \mathrm{~m}$ above sea level (ASL) at the Helena International Airport before each collection run. Larvae were sorted to morphospecies in the laboratory, using the criteria of Currie (1986). Subsets of all sample collections in Carnoy's fixative are maintained in the G.F. Shields Simuliid Collection in the Department of Natural Sciences at Carroll College, Helena, Montana. Penultimate and ultimate instar larvae of the S. arcticum complex from each site were sorted and placed in a fresh vial of Carnoy's fixative.
Polytene chromosomes of the salivary glands and gonads of each larva were stained in Feulgen (Rothfels and Dunbar 1953), and chromosome complements were scored for variation by comparing them to the standard chromosome maps for the S. arcticum complex (Shields and Procunier 1982, Adler et al. 2004). The latest progression of meiosis and the presence or absence of supernumerary or B chromosomes were determined from the same slides as those having polytene chromosomes. Since female larvae within the S. arcticum complex, excepting larvae of $S$. saxosum and $S$. apricarium, usually possess the standard chromosome sequence in each homologue, we were unable to assign females to specific siblings or cytotypes when they occurred sympatrically with other taxa of the $S$. arcticum complex. Consequently, we restricted our analyses to males. 


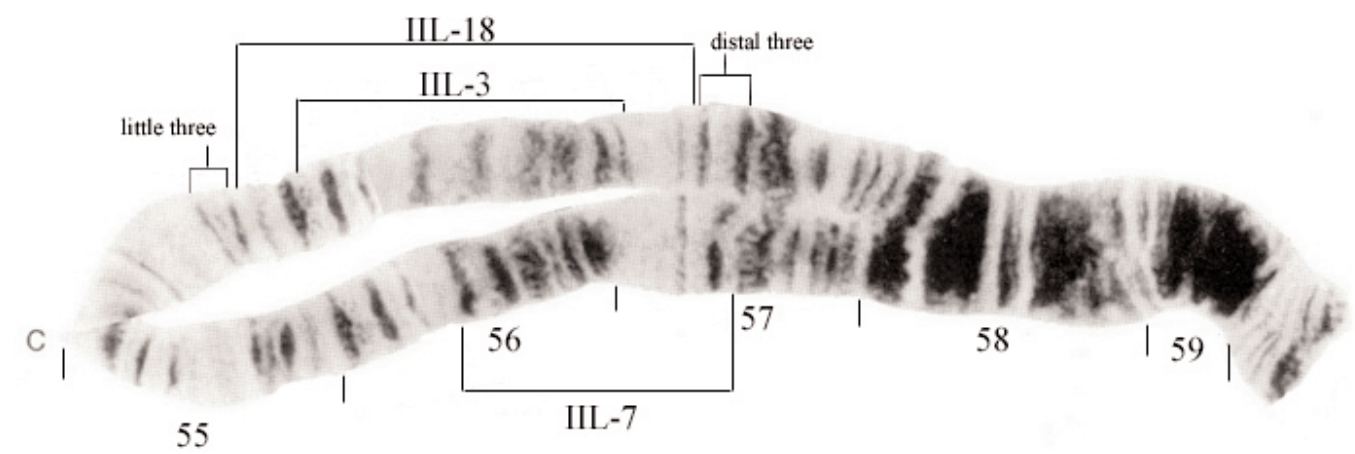

Fig. 2. The basal portion of the long arm of chromosome II of the Simulium arcticum complex showing proximal (left) and distal (right) breakpoints in brackets of the sibling-specific, sex-linked chromosomal rearrangements for taxa of this study. Simulium brevicercum possesses the standard chromosome sequence. Simulium arcticum s.s., S. apricarium, and S. arcticum IIL-18 are characterized by the IIL-3, IIL-7, and IIL-18 inversions, respectively. Numbers below the chromosome indicate sections (55-59) of this portion of the IIL chromosome. C-centromere.

TABLE 2. Mean abundances and standard errors (in parentheses) of each sibling/cytotype at each elevation.

\begin{tabular}{lcccc}
\hline Elevation & S. brevicercum & S. arcticum s.s. & S. apricarium & S. arcticum IIL-18 \\
\hline High & $14.6(4.6)$ & $23.0(11.7)$ & $0.2(0.2)$ & $2.8(1.4)$ \\
Medium & $33.8(19.9)$ & $63.2(30.8)$ & $11.8(11.1)$ & $9.0(7.8)$ \\
Low & $11.2(6.4)$ & $11.2(6.6)$ & $44.4(13.8)$ & $0.4(0.4)$ \\
\hline
\end{tabular}

For each of the 3 elevational categories, we summarized presence-absence statistics for each of the taxa and mean abundance for each of the siblings and cytotypes. Then we used analysis of variance (ANOVA) to test whether mean abundance of each sibling differed across the 3 elevations. We also used contingency analysis to test whether presence/absence for each taxon was associated with elevation (Zar 1984).

\section{Results AND Discussion \\ Cytological Description of S. arcticum IIL-18}

Simulium arcticum IIL-18 was originally described by Santoro (2004) from the Canyon Creek site (Fig. 1). The proximal breakpoint of this inversion in the long arm of chromosome II is just after the 3rd band of the "little three" in section 55, and its distal breakpoint is before the "distal three" in section 57 (Fig. 2). Meiosis in IIL-18 advances to anaphase of 1st division and this cytotype has no B chromosomes. Linkage to the $\mathrm{Y}$ chromosome is apparently complete because all 63 larvae having this specific inversion were males. Simulium arcticum IIL-18 has been found only in Granite, Jefferson, Lewis and Clark, and Powell Counties of west central Montana. It is the 3rd most abundant taxon (17.1\% of males) at the Elliston site of the Little Blackfoot River.

\section{Distributional Analysis of Major Taxa}

A total of 2839 larvae of the $S$. arcticum complex were analyzed. Of these, 720 were of siblings and cytotypes that were either absent or too infrequent at 1 or more sites to analyze here. Of the 2119 remaining larvae, 991 were female; thus, our analysis was based on 1128 male larvae of $S$. brevicercum, S. arcticum s.s., S. apricarium, and S. arcticum IIL-18. Frequency distributions of these taxa at each of the 15 collection sites are shown in Table 1 . Mean abundances for these taxa at each of the 3 elevational categories indicated that most larvae of S. apricarium (44.4) occurred at low elevations while most larvae of $S$. arcticum s.s. (63.2), S. brevicercum (33.8), and S. arcticum IIL-18 (9.0) occurred at intermediate elevations (Table 2). Analysis of variance testing for 
TABLE 3. Analysis of variance testing for the effects of elevation on abundance. The degrees of freedom for the effect and mean square error equal 2 and 12, respectively, for all dependent variables.

\begin{tabular}{lcl}
\hline & $F^{\mathrm{a}}$ & $P$ \\
\hline S. brevicercum & 0.98 & 0.405 \\
S. arcticum s.s. & 1.97 & 0.182 \\
S. apricarium & 5.02 & $0.026^{\mathrm{b}}$ \\
S. arcticum IIL-18 & 0.94 & 0.416 \\
\hline
\end{tabular}

aDependent variable $=$ abundance

bSignificant.

the effects of elevation on abundance indicated that $S$. apricarium abundance was significantly influenced by elevation (Table 3). Furthermore, $S$. apricarium abundance was significantly higher (post hoc Tukey HSD test: $P=$ $0.025)$ at low-elevation sites than at high-elevation sites.

Contingency analyses testing for differences in presence/absence of types across the 3 elevations indicated a significantly greater proportion of S. apricarium at low elevations (Fig. 3 ) and a significantly greater proportion of $S$. arcticum IIL-18 at high elevations (Fig. 4). The results support our original hypothesis that there may be elevational separation in larval habitats among the taxa. Among the 1128 larvae analyzed, only 1 individual of $S$. apricarium was found at any of the 5 high-elevation sites. Alternatively, S. apricarium was present at all low-elevation sites and abundant at 3 of these. The single $S$. apricarium male at Bison Creek (1661 m ASL) was found late in the season (15 August) and in $15^{\circ} \mathrm{C}$ water. Thus, an interplay between elevation and water temperature may influence distribution of this sibling. The formal epithet $S$. apricarium used by Adler et al. (2004) literally means "of the open" and refers to its presence in low-elevation prairie habitat. Among the 1128 male larvae identified chromosomally to sibling, only 4 S. apricarium were observed above $1475 \mathrm{~m}$, a result indicating a strong presence at low-elevation sites for this sibling.

Simulium arcticum IIL-18, though abundant only at the Elliston site and apparently localized in its distribution, was present at high elevations in greater-than-expected frequencies. Based on this finding, we suggest that $\mathrm{S}$. arcticum IIL-18 is adaptated for high elevations and the consequent colder temperatures $\left(5^{\circ} \mathrm{C}\right.$; Shields unpublished data). Simulium

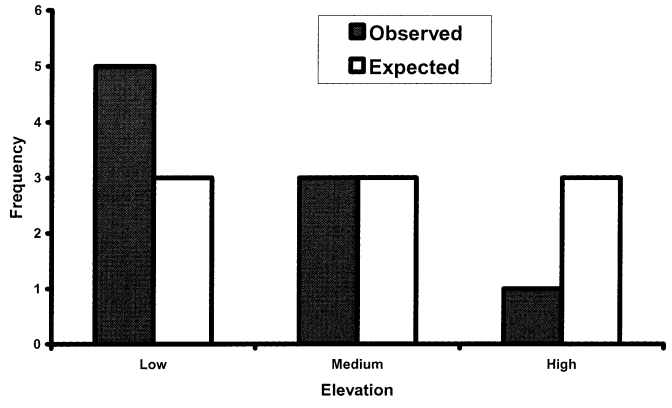

Fig. 3. Observed and expected frequencies of Simulium apricarium at low-, medium-, and high-elevation sites among the 15 sites within 5 drainages studied.

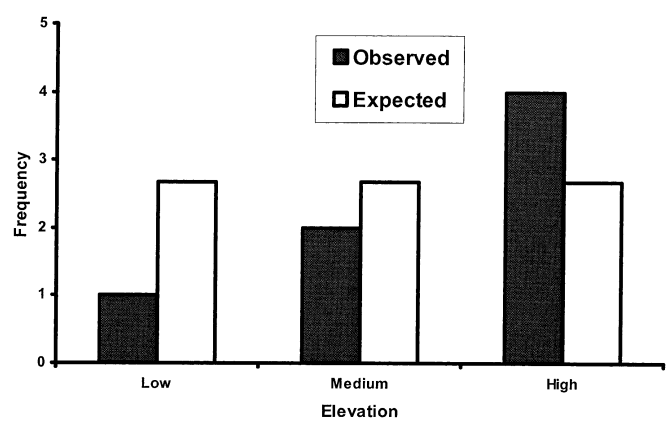

Fig. 4. Observed and expected frequencies of $S$. arcticum IIL-18 at low-, medium-, and high-elevation sites among the 15 sites within the 5 drainages studied.

arcticum IIL-18 did not occur among the larvae analyzed from the 3 sites of the Trout Creek drainage, and only 2 individuals of this cytotype occurred in the entire Boulder River drainage, albeit at intermediate and high elevations. Thus, we are reluctant to speculate on the ecological distribution of this rare cytotype. With the exceptions of Cardwell (low elevation) and Little Prickly Pear Creek and its mouth (intermediate and low elevations, respectively), S. brevicercum was found at 12 of the 15 sampled sites and S. arcticum s.s. was absent only at the Cardwell site. Thus, we suggest that these 2 siblings may not be limited by elevation or temperature.

Distributions of the 4 taxa of the $S$. arcticum complex in this study could also be influenced by their histories. Present distributions of the 4 taxa differ greatly. Simulium brevicercum has a large distribution from Alaska south 
to Alberta, Montana, Utah, and California. Simulium apricarium occurs in 9 states of the Rocky Mountain region primarily to the south and west of Montana, while S. arcticum s.s. is distributed in an area about one-third that size in Idaho, Montana, Alberta, and British Columbia primarily northwest of Montana (see Adler et al. 2004:814-822 for information on present distributions). Possibly, these siblings have come into relatively recent contact after prolonged adaptation to different environmental conditions. Alternatively, S. arcticum IIL-18 has been found at only 4 sites in a 4 -county region in west central Montana. Simulium arcticum IIL18 and 10 other cytotypes have very limited distributions in Montana (Shields unpublished data). Unlike the broadly distributed siblings mentioned above, the distributions of cytotypes and their presence with other siblings and cytotypes suggest the possibility of an in situ origin. Although allopatric speciation cannot be ruled out, the distributions of all these cytotypes could also be explained by a sympatric speciation model similar to one suggested by Rothfels (1989).

Stream velocity and depth can be predictors of the distributions of black fly species (Adler and McCreadie 1997). Thus, S. apricarium may simply be adapted to slower moving streams while $S$. arcticum IIL-18 may be adapted to more rapidly moving waters descending from higher elevations. We cannot address this issue here because each of the 5 drainages studied was chosen only for its elevational relief, and velocity and depth were not measured.

It is more likely that eggs and larvae of $S$. brevicercum, S. arcticum s.s., and S. arcticum IIL-18 "drift" downstream during and after egg deposition rather than eggs or larvae of $S$. apricarium somehow moving long distances upstream. We know little about movement of eggs after they have been laid (Adler et al. 2004), but it has been estimated that larvae of some species may drift hundreds of kilometers downstream (Rubtsov 1964).

Santoro (2004) suggested that sibling group composition within the $S$. arcticum complex was similar at 2 sites along the Little Blackfoot River. While this may be true for limited study of 2 sites at similar elevations, it is not the case when multiple drainages including sites at various elevations are studied throughout the summer as shown here.
Distribution of siblings may also be influenced by availability of nutrients concentrated at outflows (Adler and Kim 1984, Wotton 1988, McCreadie and Colbo 1992). We collected samples in the Flint Creek drainage as it flows from Georgetown Lake, Granite County (1944 m ASL), throughout the summer of 2004 and found only $S$. vittatum, which inhabits lake outflows in western North America (Adler 1986, Ciborowski and Adler 1990). The Flint Creek Campground site, at which we found only $S$. arcticum types, is only $1.6 \mathrm{~km}$ downstream from the outlet of Georgetown Lake but 335 $m$ lower in elevation. Possibly, a combination of the effects of accumulated nutrients at this lake outflow and elevation influence the distributions of both $S$. vittatum and members of the $S$. arcticum complex there.

Studies such as this may lead to the elucidation and importance of environmental cues that influence the location of egg-laying by female black flies. Based on our observations elevation may influence the distribution of S. apricarium and S. arcticum IIL-18 in west central Montana. Whether this distribution is determined by history, elevation, temperature, adaptation to local environments, or a combination of all of these factors must await additional study.

\section{ACKNOWLEDGMENTS}

The James J. Manion Fund of the Department of Natural Sciences at Carroll College provided supplies and stipends for students. The National Geographic Society (NGS grant \#7212-02 to Shields) provided funds for travel and equipment. The M.J. Murdock Charitable Trust (MJMCT grant \#2003196 to Shields) provided supplies, stipends for students, and support for travel. The Department of Natural Sciences at Carroll College provided space and equipment. We especially thank Dr. Peter H. Adler of the Department of Entomology, Clemson University, for help with identification of larvae and chromosomes and for his continued support of our work. Drs. John Addis and Grant Hokit of the Department of Natural Sciences, Carroll College, reviewed a draft of this manuscript and helped with statistical analyses, respectively. We also thank Judith Pickens and Pat, John, and Kelly Shields for help with collection of larvae. 


\section{Literature Cited}

ADLER, P.H. 1986. Ecology and cytology of some Alberta black flies (Diptera: Simuliidae). Quaestiones Entomologicael 22:1-18.

Adler, P.H., D.C. Currie, And D.M. Wood. 2004. The black flies (Simuliidae) of North America. Comstock, Cornell University Press, Ithaca, NY. 941 pp.

ADLER, P.H., AND K.C. KIM. 1984. Ecological characterization of two sibling species, IIIL-1 and IS-7, in the Simulium vittatum complex (Diptera: Simuliidae). Canadian Journal of Zoology 62:1308-1315.

AdLER, P.H., AND J.W. MCCREAdIE. 1997. The hidden ecology of black flies: sibling species and ecological scale. American Entomologist 43:153-161.

Allison, L.A., AND G.F. Shields. 1989. A cytological description of Eusimulium vernum, E. decolletum and the E. pugetense complex (Diptera: Simuliidae) in Alaska. Genome 32:550-558.

Ciborowski, J.J.H., AND P.H. AdLer. 1990. Ecological segregation of larval black flies (Diptera: Simuliidae) in northern Saskatchewan, Canada. Canadian Journal of Zoology 68:2113-2122.

Currie, D.C. 1986. An annotated list of and keys to the immature black flies of Alberta (Diptera: Simuliidae). Memoirs of the Entomological Society of Canada 134:1-90.

McCreadie, J.W., and M.H. Colbo. 1992. Spatial distribution patterns of larval cytotypes of the Simulium venustum/verecundum complex (Diptera: Simuliidae) on the Avalon Peninsula, Newfoundland; factors associated with cytotype abundance and composition. Canadian Journal of Zoology 70:1389-1396.

Newman, L.J. 1983. Sibling species of the black fly Prosimulium onychodactylum (Simuliidae, Diptera): a salivary gland chromosome study. Canadian Journal of Zoology 61:2816-2835.

Procunier, W.S. 1984. Cytological identification of pest species of the Simulium arcticum complex present in the Athabasca River and associated tributaries. Alberta Research Council Farming for the Future Final Technical Report. N. 82-101. Agriculture Canada Research Station, Lethbridge, Alberta. 44 pp.
Procunier, W.S., And J.A. Shemanchuk. 1983. Identification of sibling species of black flies in Alberta using polytene chromosome analysis. Pages 33-36 in I.J.L. Sears and T.G. Atkinson, editors, Research highlights_-1982. Agriculture Canada Research Station, Lethbridge, Alberta. 124 pp.

RothFELs, K.H. 1956. Black flies: siblings, sex and species groupings. Journal of Heredity 47:113-122.

. 1979. Cytotaxonomy of black flies (Simuliidae). Annual Review of Entomology 24:507-539. 509.

1989. Speciation in black flies. Genome 32:500

Rothfels, K.H., AND R.W. Dunbar. 1953. The salivary gland chromosomes of the black fly Simulium vittatum Zett. Canadian Journal of Zoology 31:226-241.

Rothfels, K.H., R.M. Feraday, and A. Kaneps. 1978. A cytological description of sibling species of Simulium venustum and $S$. verecundum with standard maps for the subgenus Simulium Davies (Diptera). Canadian Journal of Zoology 56:1110-1128.

RuBTSOv I.A. 1964. On the mode and range of larval black fly migrations (Diptera, Simuliidae). Entomologicheskoe Obozrenie 43:52-66. [In Russian.] English translation in Entomological Review, Washington 43:27-43.

Santoro, T.D. 2004. Cytogenetics of Simulium arcticum in west central Montana: a test of the IIL-3 "montane"/IIL-7 "prairie" hypothesis. Undergraduate thesis, Carroll College, Helena, MT.

Shields, G.F., And W.S. Procunier. 1982. A cytological description of sibling species of Simulium (Gnus) arcticum (Diptera; Simuliidae). Polar Biology 1:181192.

WotTON R.S. 1988. Very high secondary production at a lake outlet. Freshwater Biology 20:341-346.

ZAR, J.H. 1984. Biostatistical analysis. Prentice-Hall, Englewood Cliffs, NJ. 718 pp.

Received 14 November 2005 Accepted 6 July 2006 